\title{
Evaluation on Development Trend of Distributed Power Industry in China Based on Prosperity Model
}

\author{
Jun Dong, Rong Li*, Pei Wang, Qi Zhang \\ School of Economics and Management, \\ North China Electric Power University \\ No.2, Beinong Road, Huilongguan, Changping District, Beijing, 102206 \\ *lirong_huadian@163.com
}

\begin{abstract}
Distributed power generation has become an important part to develop low-carbon economy, build ecological civilization and achieve sustainable development for the countries around the world. However, with the rapid development of distributed power industry in China, there is no effective means for forecasting and early warning on its development. Especially after the explosive growth of distributed wind and photovoltaic generation installed capacity, it is urgent to put forward the model to analyze and predict the industry prosperity trend, which can provide gist for the government and stakeholders when making decisions and carrying out policies. Basing on the development situation analysis of China distributed power industry; this paper establishes the evaluation index system from five dimensions including technology, policy, market, economy and the external environment. By combining set value statistical method and diffusion index model, evaluate and predict the development of distributed power industry comprehensively from qualitative and quantitative dimensions. From the case study calculation results, we can learn that currently the distributed photovoltaic (PV) market in Jiangsu is still in the prosperity stage, but a new downturn is coming. The calculation results can also provide references and suggestions for the related industry development decision makers.
\end{abstract}

Keywords-distributed power generation; diffusion index; prosperity index model; trend prediction

\section{INTRODUCTION}

Distributed generation is an important approach to promote the development and utilization of distributed renewable energies such as wind power and solar energy, as well as to improve the efficiency of clean energy and solve the problem of power shortage in rural areas. Under the circumstance of increasing pressure from energy and environment, promoting the development of distributed energy has been one of the vital measures to deal with climate change and realize energy conservation worldwide. However, after an explosive growth of wind and photovoltaic installed capacity in China, the abandoned wind and solar energies have drawn much attention. It's urgent to analyze the prosperity tend and study the monitoring and warning of distributed energy, which can provide quantitative theoretical support for the business risks of participants after the distributed power is connected. Besides, it also can be the reference for the investors to make decisions. The research can provide the basis for the government to

This study is supported by the Fundamental Research Funds for the Central Universities under Grant (No.2017XS095) formulate distributed policies.

Currently, the research on distributed power system mainly focuses on its characteristics, energy storage technologies, economic analysis and system optimization. Li Jianlin [1], Kalkhambkar V[2] and Luo Jian[3] had the modeling research on multiple complementary technologies, cost-effectiveness and social benefits. Yang Xinglin [4] used Matlab to build the optimization model of cost and benefit, which could optimize the simulation of system unit operating mode and operating incomes. Zhang Danru[5] established a financial mathematical model to demonstrate on the economic visual that the distributed energy system were most sensitive to the changes of electricity price and gas price.

Since the researches on development trend of distributed power are rare, it is necessary to predict and prewarn the development trend of the entire industry to guide the healthy development of distributed energy. Prosperity analysis is the basis for national macroeconomic to make decisions and control the development industries and enterprises. The greater the risk of decisions making is, the more important the prosperity analysis of economy is. Although the prosperity analysis comes from the economic field and has been widely used, its application is expanding to other areas. Some of them like national scientific innovation demand side forecast, real estate and other service industries have already got achievements. Zhiguang $\mathrm{Hu}$ [6] established a prosperity index to reflect the relationship between regional economy development and electricity industry, and with the index to predict economic trend. Ma Chao and Shi Lei [7] draw up prosperity priority index and consistency index of Tianjin. So the trend of power demand in the future is predictable through the change of the priority index. However, the current prosperity index model is rarely used in distributed power research. This paper built distributed energy diffusion index model after construction and selection of distributed power index. This model can analyze whether there's a situation of overheating, overcooling or moderate of distributed power in China, and provide support for making decisions of distributed power development.

\section{StUdy ON PRosPerity INDEX OF Distributed POWER}

Evaluating the development of distributed powers not only needs to consider its technical level and economic efficiency, but also needs to comprehensively analyze political, policy 
environment and market environment. By inviting industry experts and professors to the interviews and discussions, this paper proposed indicators affecting the development of distributed powers from five aspects including technology, policy, market, economy and political environment. Specifically, those indicators were subdivided into 14 subindicators, as described below.

\section{A. Technical indicators}

1) Regional means of penetration rate: Penetration rate refers to the penetration level of one party to the other. Regional penetrance rate of distributed power $=$ current installed capacity of distributed power/area installed power.

2) Maturity of equipment technology: Maturity of equipment technology refers to the general availability of a single technology or a technology system in the research and development process.

\section{B. Policy indicators}

1) The level of subsidies: The level of subsides refers to the amount of subsidies from the government which will change with the changes of economic development.

2) Appropriation speed of subsidies allocation: This index refers to the timeliness for the project to get the subsidies which reflects the level of effective payment of subsidies.

3) Approval speed: This index refers to the time from reporting and approving by the relevant departments to the time of construction of the distributed power projects.

\section{Market Indicators}

1) Installed capacity year on year index

Installed capacity year on year index $=$ current installed capacity/capacity of the same period last year $\times 100 \%$.

\section{2) Declared quantity year on year index.}

Declared quantity year on year index = current declared quantity / declared quantity of the same period last year $\times$ $100 \%$.

\section{3) Generation year on year index}

Generation year on year index $=$ current generation volume / generation volume of the same time last year $\times 100 \%$.

4) Sales volume year on year index

Sales volume year on year index $=$ current sales volume / sales volume of the same time last year $\times 100 \%$.

\section{Economic Indicators}

1) Equipment cost benefit index: The cost of distributed power equipment includes fixed costs and variable costs. Fixed cost includes depreciation, wages and facilities maintenance costs; the variable cost includes expenditure on ancillary equipment.

Equipment cost effectiveness $=($ income-expenditure $) /$ cost $\times 100 \%$

Expenditure $=$ depreciation + maintenance costs + management costs + wages + consumptive material + other operating costs
Cost $=$ equipment value + ancillary equipment value + site fees

2) Project cost year on year index:

Project cost year on year $=($ current cost - cost of the same time last year) / cost of the same time last year $\times 100 \%$.

3) project benefit year on year index:

Project benefit year on year $=$ (current income-income of the same time last year) / income of the same time last year $\times$ $100 \%$

Project income year on year index usually grows slowly, sometimes it's even negative. While the growth is rapid in the late stage and the index is positive. Those changes reflect the development of the project's implementation.

\section{E. Political situation indicators}

1) Import and export restriction index: Import quota system is relatively important. As China's incentives for the export of distributed energy products such as photovoltaic, some of the import countries may take restrict measures which can be seen in the related export year data

2) Impact of major events : Major events means events that are enable to lead to higher media coverage, gain a good reputation and impact the economy in the host country or destinations. Major events can boost the economic development, which can significantly improve energy requirement and impact the construction of distributed powers.

\section{ESTABLISHMENT OF DISTRIBUTED POWER PROSPERITY} INDEX MODEL

\section{A. Establishing benchmarks index}

Benchmarks index can timely reflect the current economic activity of an industry. Usually, consistent indicators are used as benchmarks. Then basing on the benchmarks, classify the alternative indicators in the collection into primary index, consistent index and hysteretic index. For the distributed power industry, the generation year on year index can reflect its volatility timely and sensitively, which is the most appropriate as the benchmarks to measure the distributed power generation. The priority, consistency and hysteresis can be determined by dividing the fluctuating of different indicators relative to the benchmark and observing the order of peak and valley relative to the benchmark.

\section{B. Qualitative indicators}

Some non-quantitative indicators can't be directly used to build the model unless quantified. This paper used set valued statistics method to quantify the qualitative indicators affecting the development of distributed power supply.

Because some factors are uncertain, and lack historical data or comparisons such as approval speed, subsidies level, appropriation speed of subsidies allocation and impact of major events, usually it's hard to make accurate quantitative estimates. In this case, a certain reference standard should be given when organizing relevant experts to make a reasonable estimate of these indicators. Usually, use "approximate", "about" or "fall 
in the area between A and B" to represent the interval estimates (such as [0.3, 0.6] means between 0.3 and 0.6). These descriptions can be used to describe the uncertainty and ambiguity by the experts and recorded as $\left[u_{1}^{(k)}, u_{2}^{(k)}\right]$. Based on the scoring from the experts, Equations (1)-(2) can be used to process the set value.

$$
\begin{gathered}
\bar{u}=\frac{1}{2} \sum_{k=1}^{n}\left[\left(u_{2}^{(k)}\right)^{2}-\left(u_{1}^{(k)}\right)^{2}\right] / \sum_{k=1}^{n}\left[u_{2}^{(k)}-u_{1}^{(k)}\right] \\
g=\frac{1}{3} \sum_{k=1}^{u}\left[\left(u_{2}^{(k)}-\bar{u}\right)^{3}-\left(u_{1}^{(k)}-\bar{u}\right)^{3}\right] / \sum_{k=1}^{n}\left[u_{2}^{(k)}-u_{1}^{(k)}\right]
\end{gathered}
$$

Where, $b$ as the confidence level of $\bar{u}$, is a measure of reliability of experts' judgment, $b=\frac{1}{1+g}$.

The bigger $g$ is, the smaller confidence level $b$ will be, which shows experts are less confident in the indicators' values.

\section{Classification of indicators}

This paper uses time difference correlation analysis method to select the indexes. The time difference correlation coefficient is calculated with the growth rate of the index sequence value excluding seasonal factors and irregular factors after adjusting the season. This method is widely used during the research of prosperity index classification. The advantage is that it can dynamically reflect the long-term trend of the distributed power industry combing with the generation and situation related to various indicators basing on correlation analysis method in statistics.

Something should be noticed when choosing and selecting indicators by timing correlation method:

- The time difference correlation coefficient of each index should generally be greater than 0.5 .

- The correlation coefficient of the indexes fluctuates with obvious characteristics of periodic fluctuation.

- The correlation coefficient is not subject to symbol restrictions.

- There should be more than three months' time differences between priority index and hysteresis index.

\section{Building prosperity index}

Diffusion index (DI) is the weighted percentage value of sum of the diffusion index and semi-diffusion index and the total number of indicators. As for the growth rate after seasonal adjustment, if the growth rate of an indicator at time $t$ is bigger than the value of it in the previous $j$ months, then this indicator is diffusion index, recorded as " 1 " diffusion index. If the growth rate is equal to the value of it the previous $j$ months, then this indicator is semi-diffusion index, recorded as " 0.5 " diffusion index. If the growth rate is smaller than the value of it the previous $j$ months, then record it as " 0 " diffusion index. Add all the diffusion indexes and multiply $100 \%$, then get the value of the diffusion index at time $t$. The formula is:

$$
\mathrm{DI}(\mathrm{t})=\sum_{i=1}^{N} W i \times I[X i(t) \geq X i(t-j)] \times 100 \%
$$

In which, $\mathrm{DI}(\mathrm{t})$ is the diffusion index at time $t, \mathrm{Xi}(\mathrm{t})$ is the fluctuation measurement value of the ith variable index at time $t$, Wi is the weight of the $i$ th variable index assignment; $N$ is the number of variable indicators, $I$ is the exponential function, $j$ is the time difference of the comparative index value. If the weight is the same, then the formula will be:

$$
\mathrm{DI}(\mathrm{t})=\sum_{i=1}^{N} \frac{I[X i(t) \geq X i(t-j)]}{N} \times 100 \%
$$

The time diffusion index stays at each stage represents the spread speed at this stage. The longer the time, the slower the spread is. Its value at a certain point represents the extent and extent of economic volatility spread. The priority diffusion index, synchronic diffusion index and hysteresis diffusion index can predict and monitor the economic operation. The economic meaning of different range of diffusion index $\mathrm{Di}(\mathrm{t})$ is:

- $\quad 0<\mathrm{DI}(\mathrm{t})<50 \%$ : The economy moves to the expansion and the economy system is operating in the late recession space.

- $\quad 50 \%<\mathrm{DI}(\mathrm{t})<100 \%$ : The economy is operating in the prosperity space. A major turning point will come. As $\mathrm{Di}(\mathrm{t})$ is going closer to $100 \%$, the economy is getting booming.

- $100 \%>\mathrm{DI}(\mathrm{t})>50 \%$ : The economy is in the late prosperity space and the economy system is in the cooling stage.

- $50 \%>\mathrm{DI}(\mathrm{t})>0$ : The economy operation is at the turning point. Economy system is in a comprehensive contraction stage and going into a new recession space.

\section{EMPIRICAL ANALYSIS}

This paper used the statistical data of distributed PV projects from 2015 to 2016 in Jiangsu to build a prosperity index model, then analyzed and predicted its development trend.

\section{A. Quantify the qualitative index}

The qualitative development indicators of the distributed PV in the first quarter of 2016 were scored and calculated by the set valued statistics method mentioned before. Qualitative indicators the maturity of technology, the level of subsidies, appropriation speed of subsidies allocation and impact of major

\begin{tabular}{|c|c|c|c|c|c|}
\hline & Maturity of technology & Appropriation speed of subsidies allocation & The level of subsidies & Approval speed & Impact of major events \\
\hline Expert 1 & {$\left[\begin{array}{ll}0.3 & 0.5\end{array}\right]$} & {$\left[\begin{array}{lll}0.6 & 0.7\end{array}\right]$} & {$\left[\begin{array}{ll}0.6 & 0.8\end{array}\right]$} & {$\left[\begin{array}{lll}0.4 & 0.7\end{array}\right]$} & {$\left[\begin{array}{ll}0.4 & 0.5\end{array}\right]$} \\
\hline Expert 2 & {$\left[\begin{array}{ll}0.2 & 0.6\end{array}\right]$} & {$\left[\begin{array}{ll}0.5 & 0.8\end{array}\right]$} & {$\left[\begin{array}{ll}0.7 & 0.8\end{array}\right]$} & {$\left[\begin{array}{lll}0.5 & 0.8\end{array}\right]$} & {$\left[\begin{array}{ll}0.2 & 0.3\end{array}\right]$} \\
\hline
\end{tabular}
events were calculated according to Equations (1) and (2). Table 1 shows the scoring and evaluation in January.

TABLE I. SET VALUED ST ATIST ICS RESULT S OF JIANGSU DIST RIBUTED PV QUALIT ATIVE INDICAT ORS IN JANUARY 2016 


\begin{tabular}{|c|c|c|c|c|c|}
\hline \multicolumn{6}{|c|}{ Cont. to TABLE I } \\
\hline Expert 3 & {$\left[\begin{array}{ll}0.3 & 0.7\end{array}\right]$} & $\begin{array}{lll} & 0.4 & 0.7] \\
\end{array}$ & {$\left[\begin{array}{ll}0.5 & 0.8\end{array}\right]$} & {$\left[\begin{array}{ll}0.4 & 0.6\end{array}\right]$} & {$\left[\begin{array}{ll}0.3 & 0.4\end{array}\right]$} \\
\hline Expert 4 & $\left.\begin{array}{lll} & 0.4 & 0.7\end{array}\right]$ & $\left.\begin{array}{lll}0.4 & 0.8\end{array}\right]$ & $\left.\begin{array}{ll}0.8 & 0.9\end{array}\right]$ & $\left.\begin{array}{ll}0.5 & 0.7\end{array}\right]$ & $\left.\begin{array}{ll}0.3 & 0.5\end{array}\right]$ \\
\hline Expert 5 & {$\left[\begin{array}{ll}0.2 & 0.5\end{array}\right]$} & $\left.\begin{array}{lll}0.6 & 0.8\end{array}\right]$ & $\left.\begin{array}{ll}0.7 & 0.9\end{array}\right]$ & $\left.\begin{array}{lll}0.4 & 0.8\end{array}\right]$ & $\left.\begin{array}{lll}0.4 & 0.5\end{array}\right]$ \\
\hline Expert 6 & {$\left[\begin{array}{ll}0.3 & 0.6\end{array}\right]$} & {$\left[\begin{array}{ll}0.5 & 0.8\end{array}\right]$} & {$\left[\begin{array}{ll}0.6 & 0.7\end{array}\right]$} & {$\left[\begin{array}{ll}0.6 & 0.8\end{array}\right]$} & {$\left[\begin{array}{ll}0.4 & 0.6\end{array}\right]$} \\
\hline Expert 7 & {$\left[\begin{array}{ll}0.5 & 0.7\end{array}\right]$} & {$\left[\begin{array}{ll}0.7 & 0.8\end{array}\right]$} & {$\left[\begin{array}{ll}0.6 & 0.8\end{array}\right]$} & {$\left[\begin{array}{ll}0.6 & 0.7\end{array}\right]$} & {$\left[\begin{array}{ll}0.5 & 0.6\end{array}\right]$} \\
\hline Expert 8 & $\left.\begin{array}{lll}0.4 & 0.6\end{array}\right]$ & $\left.\begin{array}{lll}0.5 & 0.7\end{array}\right]$ & $\left.\begin{array}{ll}0.5 & 0.8\end{array}\right]$ & $\left.\begin{array}{lll}0.5 & 0.7\end{array}\right]$ & $\left.\begin{array}{lll}0.4 & 0.7\end{array}\right]$ \\
\hline Expert 9 & {$\left[\begin{array}{ll}0.5 & 0.6\end{array}\right]$} & $\left.\begin{array}{lll} & 0.6 & 0.7\end{array}\right]$ & $\left.\begin{array}{ll}0.6 & 0.9\end{array}\right]$ & $\left.\begin{array}{lll}0.4 & 0.7\end{array}\right]$ & {$\left[\begin{array}{ll}0.6 & 0.7\end{array}\right]$} \\
\hline Expert 10 & $\left.\begin{array}{lll} & 0.4 & 0.5\end{array}\right]$ & $\left.\begin{array}{lll} & 0.4 & 0.8\end{array}\right]$ & $\left.\begin{array}{lll}0.8 & 0.9\end{array}\right]$ & $\left.\begin{array}{lll}0.5 & 0.6\end{array}\right]$ & $\left.\begin{array}{lll}0.5 & 0.7\end{array}\right]$ \\
\hline $\bar{\mu}$ & 0.466 & 0.625 & 0.718 & 0.593 & 0.490 \\
\hline $\mathrm{b}$ & 0.987 & 0.990 & 0.991 & 0.991 & 0.986 \\
\hline
\end{tabular}

Similarly, Table 2 shows set valued statistics results of distributed PV in Jiangsu qualitative indicators from February to December in 2016.

TABLE II. SET VALUED ST ATIST ICS RESULT S OF JIANGSU DIST RIBUTED PV QUALIT ATIVE INDICATORS FROM FEBRUARY TO DECEMBER IN 2016

\begin{tabular}{|c|c|c|c|c|c|}
\hline & Maturity of technology & Appropriation speed of subsidies allocation & The level of subsidies & Approval speed & Impact of major events \\
\hline Feb & 0.407 & 0.425 & 0.608 & 0.428 & 0.32 \\
\hline Mar & 0.503 & 0.545 & 0.658 & 0.507 & 0.40 \\
\hline Apr & 0.569 & 0.605 & 0.626 & 0.589 & 0.48 \\
\hline May & 0.669 & 0.725 & 0.709 & 0.698 & 0.53 \\
\hline Jun & 0.527 & 0.525 & 0.648 & 0.537 & 0.48 \\
\hline Jul & 0.409 & 0.425 & 0.543 & 0.439 & 0.40 \\
\hline Aug & 0.635 & 0.675 & 0.608 & 0.664 & 0.49 \\
\hline Sep & 0.508 & 0.485 & 0.502 & 0.453 & 0.36 \\
\hline Oct & 0.676 & 0.595 & 0.695 & 0.529 & 0.45 \\
\hline Nov & 0.706 & 0.625 & 0.704 & 0.568 & 0.55 \\
\hline Dec & 0.726 & 0.705 & 0.718 & 0.705 & 0.55 \\
\hline
\end{tabular}

\section{B. Pretreat of indicators}

The consistency index-power generation year on year index fluctuates significantly in July and October 2016, which was out of the overall trend of the entire data. Since it was not conductive to the sequence analysis of the trend, pretreatment was necessary. This paper used exponential smoothing method to revalued data of these two months, shown in Table 3. Table 4 shows a summary of market indicators.

TABLE III. YEAR ON YEAR ORIGINAL VALUE AND CORRECTION VALUE OF POWER GENERATION OF DIST RIBUTED PV IN JIANGSU IN 2016

\begin{tabular}{|c|c|c|}
\hline & Year on year original value of power generation & Year on year correction value of power generation \\
\hline Jan & 115.3 & 115.3 \\
\hline Feb & 112 & 112 \\
\hline Mar & 109 & 109 \\
\hline Apr & 90 & 90 \\
\hline May & 110 & 110 \\
\hline Jun & 134 & 134 \\
\hline Jul & 1800 & 126 \\
\hline Aug & 50 & 50 \\
\hline Sep & 40 & 40 \\
\hline Oct & 360 & 50 \\
\hline Nov & 60 & 60 \\
\hline Dec & 130 & 130 \\
\hline
\end{tabular}

TABLE IV. VALUE SUMMARY OF DIST RIBUTED PV MARKET INDEX IN JIANGSU IN 2016

\begin{tabular}{|c|c|c|c|c|}
\hline & Generation year on year index & Sales volume year on year index & Installed capacity year on year index & Declared quantity year on year index \\
\hline Jan & 115.3 & 110 & 120 & 112.85 \\
\hline Feb & 112 & 90 & 80 & 110 \\
\hline Mar & 109 & 120 & 130 & 103.50 \\
\hline Apr & 90 & 100 & 120 & 102.67 \\
\hline May & 110 & 120 & 97 & 98.84 \\
\hline Jun & 134 & 120 & 115 & 126.37 \\
\hline Jul & 126 & 114 & 109 & 118.5 \\
\hline Aug & 50 & 60 & 59 & 33.56 \\
\hline Sep & 40 & 38 & 36 & 23.57 \\
\hline Oct & 50 & 56 & 72 & 59 \\
\hline Nov & 60 & 70 & 90 & 74.04 \\
\hline Dec & 130 & 140 & 150 & 114.63 \\
\hline
\end{tabular}

\section{Indicator classification}

This paper use timing correlation method to classify the indicators. Through calculating the yearly correlation of each index and generation volume of benchmarks (shown in Table 5), the Lag value corresponding to the biggest absolute value is available, which can help to determine the priority and 
hysteresis of indicators. The results of the classification of the indicators are shown in Table 6.

TABLE V. INTERRELATIONSHIP T ABLE OF EVALUATION INDICATORS AND YEAR ON YEAR GENERATION INDEX OF THE DISTRIBUT ED PV IN JIANGSU

\begin{tabular}{|c|c|c|}
\hline Division of indicators & Priority or hysteresis & The maximum value of the correlation coefficient \\
\hline Sales year on year index & 0 & 0.941 \\
\hline Installed capacity year on year index & 0 & 0.805 \\
\hline Declared quantity year on year index & 0 & 0.95 \\
\hline Regional penetration rate year on year index & 0 & 0.992 \\
\hline Technical maturity & 1 & 0.569 \\
\hline Subsidy allocation speed & -2 & 0.436 \\
\hline subsidy level & -2 & 0.61 \\
\hline approval speed & -5 & 0.326 \\
\hline Import and export restriction index & -2 & 0.832 \\
\hline Major event impact & -1 & 0.404 \\
\hline Equipment cost-effectiveness index & 2 & 0.759 \\
\hline Project cost index & -2 & 0.743 \\
\hline Project Revenue Index & 2 & 0.592 \\
\hline
\end{tabular}

TABLE VI. SUMMARY RESULTS OF PROSPERITY INDEX

\begin{tabular}{|c|c|c|c|}
\hline & Priority index & Consistency index & Hysteresis index \\
\hline Sub-indicators & $\begin{array}{l}\text { Subsidy allocation speed } \\
\text { subsidy level } \\
\text { approval speed } \\
\text { Import and export restriction index } \\
\text { Major event impact } \\
\text { Project cost index }\end{array}$ & $\begin{array}{l}\text { Sales year on year index } \\
\text { Installed capacity year on year index } \\
\text { Declared quantity year on year index } \\
\text { Regional penetration rate year on year index }\end{array}$ & $\begin{array}{l}\text { Technical maturity } \\
\text { Equipment cost-effectiveness index } \\
\text { Project Revenue Index }\end{array}$ \\
\hline
\end{tabular}

\section{D. prosperity diffusion index}

Basing on the classification in Table 6, after reorganizing those 14 indicators in accordance with priority, consistency and hysteresis, calculate the development speed of link-relative, as shown in Table 7. Then calculate the diffusion index of each classification according to formula (4). The results are shown in Table 8.

TABLE VII. MONTH ON MONTH DEVELOPMENT SPEED OF ALL THE INDICATORS

\begin{tabular}{|c|c|c|c|c|c|c|c|c|c|c|c|c|c|}
\hline \multirow[b]{2}{*}{ Time } & \multicolumn{6}{|c|}{$\begin{array}{l}\text { Priority index } \\
\end{array}$} & \multicolumn{4}{|c|}{ Consistency index } & \multicolumn{3}{|c|}{ Hysteresis index } \\
\hline & $\begin{array}{l}\text { Subsidy } \\
\text { level } \\
\text { X1 }\end{array}$ & $\begin{array}{l}\text { Approval } \\
\text { speed X2 }\end{array}$ & $\begin{array}{c}\text { Subsidy } \\
\text { allocation } \\
\text { speed X3 }\end{array}$ & $\begin{array}{l}\text { Export } \\
\text { year } \\
\text { on } \\
\text { year } \\
\text { index } \\
\mathrm{X} 4\end{array}$ & $\begin{array}{c}\text { Major } \\
\text { event } \\
\text { impact } \\
\text { X5 }\end{array}$ & $\begin{array}{c}\text { Project } \\
\text { cost } \\
\text { year } \\
\text { on } \\
\text { year } \\
\text { index } \\
\text { X6 }\end{array}$ & $\begin{array}{l}\text { Regional } \\
\text { penetration } \\
\text { rate year } \\
\text { on year } \\
\text { index X7 }\end{array}$ & $\begin{array}{l}\text { Sales } \\
\text { year } \\
\text { on } \\
\text { year } \\
\text { index } \\
\text { X8 }\end{array}$ & $\begin{array}{c}\text { Installed } \\
\text { capacity } \\
\text { year on } \\
\text { year } \\
\text { indexX9 }\end{array}$ & $\begin{array}{c}\text { Declared } \\
\text { quantity } \\
\text { year on } \\
\text { year } \\
\text { index } \\
\text { X10 }\end{array}$ & $\begin{array}{c}\text { Technical } \\
\text { maturity } \\
\text { X11 }\end{array}$ & $\begin{array}{l}\text { Equipment } \\
\text { cost- } \\
\text { effectiveness } \\
\text { year on year } \\
\text { index X12 }\end{array}$ & $\begin{array}{c}\text { Project } \\
\text { Revenue } \\
\text { Index } \\
\text { X13 }\end{array}$ \\
\hline $\begin{array}{l}\text { Jan, } \\
2016 \\
\end{array}$ & 1.000 & 1.000 & 1.000 & 1.000 & 1.000 & 1.000 & 1.000 & 1.000 & 1.000 & 1.000 & 1.000 & 1.000 & 1.000 \\
\hline $\begin{array}{c}\text { Feb, } \\
2016\end{array}$ & 0.847 & 0.848 & 0.680 & 0.890 & 0.816 & 0.760 & 0.971 & 0.818 & 0.667 & 0.975 & 0.873 & 1.000 & 0.809 \\
\hline $\begin{array}{l}\text { Mar, } \\
2016\end{array}$ & 1.082 & 1.139 & 1.282 & 1.133 & 1.050 & 1.267 & 0.983 & 1.333 & 1.625 & 0.941 & 1.236 & 1.000 & 1.194 \\
\hline $\begin{array}{l}\text { Apr, } \\
2016\end{array}$ & 0.951 & 1.052 & 1.110 & 1.141 & 1.190 & 1.460 & 0.878 & 0.833 & 0.923 & 0.992 & 1.131 & 0.761 & 0.907 \\
\hline $\begin{array}{l}\text { May, } \\
2016 \\
\end{array}$ & 1.133 & 1.158 & 1.198 & 0.941 & 1.060 & 0.939 & 1.175 & 1.200 & 0.808 & 0.963 & 1.176 & 1.000 & 1.467 \\
\hline $\begin{array}{l}\text { Jun, } \\
2016 \\
\end{array}$ & 0.914 & 0.850 & 0.724 & 0.788 & 0.906 & 0.548 & 1.223 & 1.000 & 1.186 & 1.279 & 0.788 & 1.000 & 0.779 \\
\hline $\begin{array}{c}\text { Jul, } \\
2016\end{array}$ & 0.838 & 1.000 & 0.810 & 0.970 & 0.938 & 0.949 & 0.934 & 0.950 & 0.948 & 0.938 & 0.776 & 1.469 & 0.681 \\
\hline $\begin{array}{l}\text { Aug, } \\
2016\end{array}$ & 1.120 & 1.024 & 1.588 & 1.068 & 1.089 & 1.077 & 0.469 & 0.526 & 0.541 & 0.283 & 1.553 & 1.000 & 1.494 \\
\hline $\begin{array}{l}\text { Sep, } \\
2016\end{array}$ & 0.826 & 0.829 & 0.719 & 1.087 & 0.898 & 1.066 & 0.933 & 0.633 & 0.610 & 0.702 & 0.800 & 1.000 & 0.584 \\
\hline $\begin{array}{c}\text { Oct, } \\
2016\end{array}$ & 1.384 & 1.278 & 1.227 & 1.114 & 1.182 & 1.840 & 0.893 & 1.474 & 2.000 & 2.503 & 1.331 & 0.510 & 2.068 \\
\hline $\begin{array}{l}\text { Nov, } \\
2016 \\
\end{array}$ & 1.013 & 1.092 & 1.050 & 1.002 & 1.058 & 1.014 & 1.300 & 1.250 & 1.250 & 1.255 & 1.044 & 1.000 & 1.026 \\
\hline $\begin{array}{l}\text { Dec, } \\
2016\end{array}$ & 1.020 & 1.004 & 1.128 & 1.008 & 1.000 & 0.992 & 1.969 & 2.000 & 1.667 & 1.548 & 1.028 & 1.000 & 1.014 \\
\hline
\end{tabular}


TABLE VIII. MONTH ON MONTH DEVELOPMENT SPEED OF ALL THE INDICATOR

\begin{tabular}{|c|c|c|c|c|c|c|c|c|c|c|c|c|c|c|c|c|}
\hline \multirow{3}{*}{ Time } & \multicolumn{7}{|c|}{ Priority index } & \multicolumn{5}{|c|}{ Consistency index } & \multicolumn{4}{|c|}{ Hysteresis index } \\
\hline & $\mathrm{X} 1$ & $\mathrm{X} 2$ & $\mathrm{X} 3$ & $\mathrm{X} 4$ & $\mathrm{X} 5$ & $\mathrm{X} 6$ & & $\mathrm{X} 7$ & $\mathrm{X} 8$ & $\mathrm{X} 9$ & $\mathrm{X} 10$ & & X11 & $\mathrm{X} 12$ & $\mathrm{X} 13$ & \\
\hline & $\mathrm{I}(\mathrm{t})$ & $\mathrm{I}(\mathrm{t})$ & $\mathrm{I}(\mathrm{t})$ & $\mathrm{I}(\mathrm{t})$ & $\mathrm{I}(\mathrm{t})$ & $\mathrm{I}(\mathrm{t})$ & Priority DI & $\mathrm{I}(\mathrm{t})$ & $\mathrm{I}(\mathrm{t})$ & $\mathrm{I}(\mathrm{t})$ & $\mathrm{I}(\mathrm{t})$ & Consistency DI & $\mathrm{I}(\mathrm{t})$ & $\mathrm{I}(\mathrm{t})$ & $\mathrm{I}(\mathrm{t})$ & Hysteresis DI \\
\hline Jan, 2016 & 0.5 & 0.5 & 0.5 & 0.5 & 0.5 & 0.5 & 0.50 & 0.5 & 0.5 & 0.5 & 0.5 & 0.50 & 0.5 & 0.5 & 0.5 & 0.50 \\
\hline Feb, 2016 & 0.0 & 0.0 & 0.0 & 0.0 & 0.0 & 0.0 & 0.00 & 0.0 & 0.0 & 0.0 & 0.0 & 0.00 & 0.0 & 0.5 & 0.0 & 0.17 \\
\hline Mar, 2016 & 1.0 & 1.0 & 1.0 & 1.0 & 1.0 & 1.0 & 1.00 & 0.5 & 1.0 & 1.0 & 0.0 & 0.63 & 1.0 & 0.5 & 1.0 & 0.83 \\
\hline Apr, 2016 & 0.0 & 0.0 & 0.0 & 1.0 & 1.0 & 1.0 & 0.50 & 0.0 & 0.0 & 0.0 & 1.0 & 0.25 & 0.0 & 0.0 & 0.0 & 0.00 \\
\hline May, 2016 & 1.0 & 1.0 & 0.5 & 0.0 & 0.0 & 0.0 & 0.42 & 1.0 & 1.0 & 0.0 & 0.0 & 0.50 & 0.5 & 1.0 & 1.0 & 0.83 \\
\hline Jun, 2016 & 0.0 & 0.0 & 0.0 & 0.0 & 0.0 & 0.0 & 0.00 & 1.0 & 0.0 & 1.0 & 1.0 & 0.75 & 0.0 & 0.5 & 0.0 & 0.17 \\
\hline Jul, 2016 & 0.0 & 1.0 & 1.0 & 1.0 & 0.5 & 1.0 & 0.75 & 0.0 & 0.0 & 0.0 & 0.0 & 0.00 & 0.5 & 1.0 & 0.0 & 0.50 \\
\hline Aug, 2016 & 1.0 & 0.5 & 1.0 & 1.0 & 1.0 & 1.0 & 0.92 & 0.0 & 0.0 & 0.0 & 0.0 & 0.00 & 1.0 & 0.0 & 1.0 & 0.67 \\
\hline Sep, 2016 & 0.0 & 0.0 & 0.0 & 0.5 & 0.0 & 0.5 & 0.17 & 1.0 & 0.0 & 0.0 & 1.0 & 0.50 & 0.0 & 0.5 & 0.0 & 0.17 \\
\hline Oct, 2016 & 1.0 & 1.0 & 1.0 & 1.0 & 1.0 & 1.0 & 1.00 & 0.0 & 1.0 & 1.0 & 1.0 & 0.75 & 0.0 & 0.0 & 0.0 & 0.00 \\
\hline Nov, 2016 & 0.0 & 0.0 & 0.0 & 0.0 & 0.0 & 0.0 & 0.00 & 1.0 & 0.5 & 1.0 & 0.0 & 0.63 & 0.5 & 1.0 & 0.0 & 0.50 \\
\hline Dec, 2016 & 0.5 & 0.5 & 1.0 & 0.5 & 1.0 & 0.0 & 0.58 & 1.0 & 1.0 & 1.0 & 1.0 & 1.00 & 1.0 & 0.5 & 0.5 & 0.67 \\
\hline
\end{tabular}

\section{E. Result Analysis}

According to the diffusion index (Table 8), the comparison chart of the priority, consistency and hysteresis is shown in Fig. 1 .

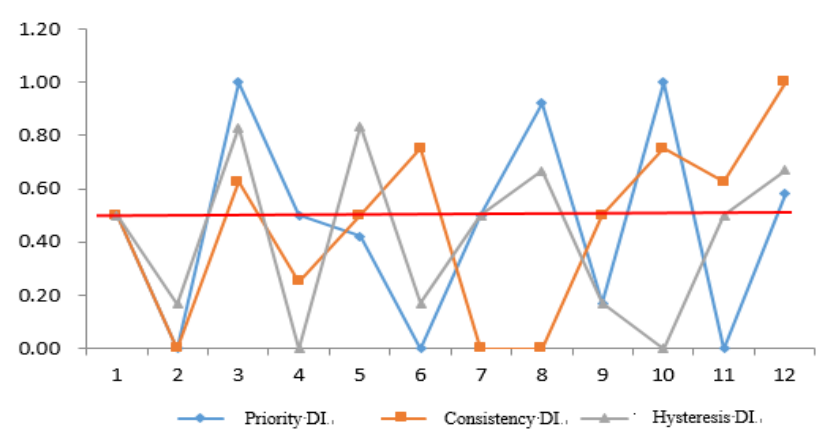

Fig. 1. Comparison chart of diffusion index

1) Analysis on consistency diffusion index: The consistency diffusion index of distributed power in Jiangsu presents the current status and development level of PV. The prosperity status of its development can be determined by the running trajectory. As is shown in Fig. 1, there were four cycles of the distributed PV in Jiangsu from January to December in 2016. Each cycle had three stages: prosperity-recession-prosperity, and each lasts for three months. From March to June, the PV in Jiangsu experienced a complete prosperity cycle with a small peak-valley gap, which means the market developed steadily and the oscillation degree is low. The fluctuation of the period of June to September was more intense since the PV market in Jiangsu has been affected by strong uncertainties The diffusion index in September was 0.5 and over 0.5 from October, which means the development in September reached the bottom. Most indicators started to rise since October, and the prosperity interval was in an expansion phase.

2) Analysis on priority diffusion index: Priority index can forecast the possible prosperity turning point, which can help predicting the short-term prosperity development of the future. It will solve the problem that synchronization index can't predict the future effectively. According to the comparison of priority index and synchronization index in Fig. 1, the trends of these two indexes are basically the same. Overall, the changes of priority index occur one to two months earlier than that of the synchronization index. After April, the diffusion index started going down, the PV in Jiangsu developed to a turning stage. As a result, the consistency index also showed a downward trend and the recession continued in July and August. The priority cross the critical line from bottom to top in July, indicating that the industry starts turning from recession to prosperity. The development of PV in Jiangsu began to improve, because all the indicators were in a rising state and in the expansion phase.

3) Analysis on hysteresis diffusion index: The hysteresis diffusion index can verify the integrity of the prosperity cycle. At the same time, it can test the accuracy of the prosperity status identified by priority index and synchronous index.As can be seen in Fig. 1, the trend of hysteresis index is basically the same as the synchronization index. However, the hysteresis index is generally behind the synchronic spread index for 1-2 months due to the lag. Considering the prosperity cycle of the hysteresis index, it began to going down since September, which coincided with the market prosperity status in July. The hysteresis index reached a slump bottom in October, but the performance was boom up and would enter the recovery phase, which coincided with the recession stage in August.

On the whole, during January to December, the priory diffusion index, consistency diffusion index and hysteresis diffusion index of distributed PV in Jiangsu had basically the same trend and there are 1 to 2 months or so interval difference. Considering the interaction among the index systems and the synchronous diffusion index, currently, the distributed PV market in Jiangsu is still in the prosperity stage. According to the comparison of priory diffusion index and synchronous diffusion index, it can be predicted that the current situation of Jiangsu will change, and the new downturn is coming. Using the hysteresis diffusion index or synchronous index, get basically the same with actual situation of distributed PV in Jiangsu.

\section{CONCLUSION AND SUGGESTION}

Considering the circumstance of low-carbon development, distributed power will be the primary field of electricity construction in China. In order to ensure the healthy and orderly development of distributed power, scientific theories are required to comprehensively forecast and monitor the prosperity development of distributed power, which can also 
provide support and basis for the relevant policies and management norms timely and scientifically. This paper proposed a multi-dimensional way to forecast the prosperity index of distributed power generation basing on its characteristic and development status and furtherly calculate, and evaluated the assessment indicators of distributed power propensity situations. A three-level index system was built from five prospects: technology, policy, market, economy and political environment. Basing on the index system, the paper used centralization statistical method to evaluate the prosperity qualitative index of distributed power and build the prosperity index which can determine and predict the prosperity situation of the distributed power qualitatively and quantitatively. The prosperity evaluation model can be used to analyze and predict different types of distributed power supply in different regions or different provinces and provide reference and support for related stakeholders when making decisions.

\section{REFERENCES}

[1] Li Jianlin, Tian Liting, and Li Chunlai, “Key Technology of Distributed Energy Generation and Reactive Energy Distribution,” Electrotechnical Application, vol. 9, pp. 28-33, May 2015.(In Chinese)

[2] Kalkhambkar V, Kumar R, and Bhakar R "Joint optimal allocation methodology for renewable distributed generation and energy storage for economic benefits," IET Renewable Power Generation, vol. A 10, pp. 1422-1429, 2016.

[3] Luo Jian, Yu Xuehai, and Zhang Zhansuo "Analysis on Development Prospect and Economic Efficiency of Gas Distribution Energy,” Gas Turbine Technology, vol. A25, pp. 17-19, June 2012.(In Chinese)

[4] Yang Xinglin, Luo Xingxing, and Wang Yubao "Research on Economical Optimization Modeling of Distributed Energy System," Journal of Jiangsu University of Science and Technology: Natural Science Edition, vol. 2, pp. 138-142, April 2015.(In Chinese)

[5] Zhang Danru, and Song Yueping "Economic Feasibility Analysis of Distributed Energy Project in an Industrial Park," Building Energy Efficiency, vol. 1, pp. 120-124, February 2015.(In Chinese)

[6] $\mathrm{Hu} \mathrm{Z}$, Yang J, Wang S, and Zhong Z "Regional economic growth forecasting based on partial least square, support vector machine and prosperity index method," Youth Academic Annual Conference of IEEE, 2017, pp: 454-458.

[7] Ma Chao, Shi Lei, Wang Ying, Luo Xin, and Zhao Bo "Research and Application of Tianjin Electric Power Prospective Exponent Model," Electric Age, vol. 1, pp. 88-90+95, January 2017.(In Chinese) 